\title{
Genome research risks abuse, panel warns
}

London. A panel set up by two US government departments to examine the social implications of the Human Genome Project (HGP) has issued a warning that research funded by the project could be used to support demands for cuts in public funding for social welfare programmes.

The warning comes in a statement from the working group on the ethical, legal and social implications of human genome research - known as the ELSI working group - set up jointly by the National Institutes of Health (NIH) and the Department of Energy, the two agencies jointly responsible for funding the HGP.

The statement is aimed at the arguments raised last year by Richard Herrnstein of Harvard University, and Charles Murray, of the American Enterprise Institute (AEI), in their controversial book The Bell Curve, which has already sold more than 400,000 copies. This claims that many social welfare programmes have failed to achieve their objective because they refuse to acknowledge inherent differences in intellectual ability between different social groups.

While distancing themselves from earlier eugenics thinking about the need to eliminate undesirable human traits, the two authors draw heavily on the results of research into the links between inherited characteristics and social behaviour in developing their conclusions.

But in its statement, the ELSI working group claim that genetic arguments cannot and should not be used to inform social policy in the areas cited by Herrnstein and Murray. "Since the lessons of genetics are not deterministic, they do not provide useful information on deciding whether or not to pursue various programmes to enhance the capabilities of different members of society," says the statement. "Those decision are moral, social and political ones."

Although The Bell Curve was published last year, distribution of the ELSI statement is said to have been delayed by a vigorous debate inside the NIH over how far the agency should become involved in what some claim to be a largely political dispute.

Those responsible for the statement, however, remain convinced of the importance of taking a stand. It has, for example, already been endorsed by the National Society of Genetic Counsellors, many of whose members are concerned that fears of seeing social welfare removed from those considered to have the 'wrong' genetic traits could threaten the social acceptability of therapeutic genetic screening.

"We believe that [The Bell Curve] is inappropriately drawing legitimacy from the success of the HGP, misrepresenting the state of genetic knowledge in the area of

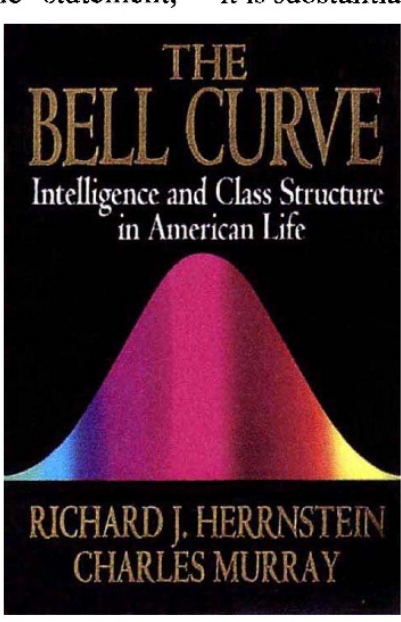

The Bell Curve: under attack by the genome ethics group. tion with genetic decline by "exerting downward pressure on the distribution of cognitive ability in the United States".

It points out that research into the complex relationship between genetic and environmental influences on cognitive ability is still evolving and faces many methodological difficulties. To conclude that cognitive ability cannot be changed because it is substantially heritable, and that remedibehavioural genetics, and misusing this information to inform social policy," says Lori B. Andrews, a law professor at the University of Chicago and the chair of the working group.

The statement itself concentrates in particular on the claim by Herrnstein and Murray that high birth rates among the poor, combined with the "dysgenic" behaviour of women with high IQs producing fewer offspring, are threatening the populament on the specific claims made by the

\section{Medical rivals consider joint operations}

San Francisco. Stanford University in Stanford, California, and the University of California, San Francisco (UCSF), rivals both on the football field and in the laboratory, may soon collaborate on patient care and medical teaching. Tentative discussions about possible collaboration are the latest in a series of moves by teaching hospitals to adapt to a private health-care system that is becoming increasingly demanding, at a time when federal and state funds are dwindling.

Both institutions have been silent on the specifics of their future relationship. But Joseph B. Martin, chancellor of UCSF, and Gerhard Casper, president of Stanford, said they would focus on economies of scale and preventing duplicated investment in new facilities and equipment. The two medical schools and their faculties would remain independent, with clinical services continuing at both sites.
Eugene Bauer, dean of the Stanford School of Medicine, has told the faculty that a partnership with UCSF would strengthen both institutions. "We have an enormous opportunity, not only to cooperate clinically, but in providing the highest level of medical education in the country." Together, the universities may also increase their ability to cooperate with industry, he said.

Senior faculty and staff at Stanford say they need to focus on improving biomedical research, teaching and clinical care in the face of declining revenues. The faculty may have to shrink while becoming more efficient, they said in a 'vision statement' from a faculty retreat last month.

Casper said that the collaboration aimed to provide a critical mass for teaching in small specialty programmes and more diverse clinical training opportunities at both schools.
Sally Lehrman al education is therefore not worth the effort or the cost, "is neither an accurate message from genetics nor a necessary lessons from efforts at remedial education".

Furthermore, says the working group, a lack of predictability from genetic information is the rule rather than the exception. "Simplistic aims about the inheritance of such a complex trait as cognitive ability are unjustifiable; moreover, as the history of eugenics shows, they are dangerous."

Not surprisingly, the authors have strongly rejected the claims that their conclusions are unscientific - or that they have behaved unethically by discussing the role of genetic influences on social behaviour in general, and cognitive ability in particular.

Although the authors decline to comELSI working group, a spokesperson for the AEI dismissed such claims on Monday as being based on "cocktail party discussion" of their book's contents. "The book is more about cycles of poverty than genetics," she said. "It does not have any bearing on the research agenda of the NIH."

Nevertheless, members of the group remain adamant that its concerns need to be taken on board by professional geneticists. Speaking at a meeting at Stanford University at the beginning of last month, for example, Troy Duster, professor of sociology at the University of California, Berkeley, pointed out that the American Society of Human Genetics had declined to sign the working group's statement, claiming that it lacked the expertise to refute the statistical methods used in its calculations.

There was also a warning from David Cox, professor of genetics at Stanford and a key participants in the HGP, as well as a member of the ELSI working group. Discussing the ethical issues raised by the equally controversial Human Genome Diversity Project (see Nature 377, 373; 1995), Cox said he was becoming increasingly aware of the extent to which the public tended to see genetic findings as deterministic. "We have a big problem here," he said. 